\title{
Effect of cooling rates of production process of Al-3\%B-3\%Sr master alloy on grain refinement and eutectic modification efficiency in cast A356 alloy
}

\author{
Krittee eidhed ${ }^{1, *}$ and Phisith muangnoy ${ }^{1}$ \\ ${ }^{1}$ Department of Materials and Production Technology Engineering, Faculty of Engineering, King Mongkut's University of Technology \\ North Bangkok, Bangkok, Thailand
}

\begin{abstract}
In this paper, size and morphology of the grain refiner and modifier particles in the $\mathrm{Al}-3 \% \mathrm{~B}-$ $3 \% \mathrm{Sr}$ master alloy production by using different cooling rates were investigated. Two $\mathrm{Al}-3 \% \mathrm{~B}-3 \% \mathrm{Sr}$ master alloys were produced with 0.2 and $10^{\circ} \mathrm{C} / \mathrm{s}$, respectively. The grain refinement and eutectic modification efficiency of the Al-3\%B-3\% Sr master alloy were tested in casting process of A356 alloy by addition of 4wt.\% and holding times for 10-120 min. The experimental result showed that microstructure of the M1 alloy (Slow cooling) consisted of larger solidified particles of $\mathrm{AlB}_{2}, \mathrm{SrB}_{6}$ and $\mathrm{Al} 4 \mathrm{Sr}$ in the matrix of $\alpha$-Al compared to the M2 alloy (Rapid cooling). The addition of the M1 alloy in cast A356 alloy, it was found that small grain size and fully modify eutectic silicon were obtained from the holding time in a range of 10$60 \mathrm{~min}$. While the addition of M2 alloy, a small grain size was achieved in shorter holding time in a range of 10-30 min but the eutectic silicon was partly modify. From the thermal analyzed result, solidification of un-modified A356 alloy was changed after addition of Al-3\%B-3\% Sr master alloy. It was clearly observed that both the undercooling of nucleation and eutectic reaction was reduced and the solidification time was shifted to longer.
\end{abstract}

\section{Introduction}

$\mathrm{Al}-\mathrm{Si}-\mathrm{Mg} / \mathrm{Al}-\mathrm{Si}-\mathrm{Cu}$ based alloys are widely used for cast complex part because of an excellent castability, resistance to hot tearing in casting, enhance mechanical properties by using the precipitation strengthening by controlling the precipitated particle of $\mathrm{Mg}_{2} \mathrm{Si}$ or $\mathrm{Al}_{2} \mathrm{Cu}$ [1]. There are two melt treatment processes in casting of hypoeutectic Al-Si based alloy. One is the grain refinement process by the addition of grain refiner such as Al-Ti, Al-Ti-C, Al-Ti-B, Al-B master alloys [2-4]. A fine $\alpha-\mathrm{Al}$ grain is achieved by producing of heterogeneous nucleation site in the melt during it solidified in the mold [5-6]. Second, the eutectic modification process by addition of modifier such as AlSr alloy [7]. The eutectic modification process can be improvement mechanical properties, the die filling, controlling the porosity distribution [7-8] and reducing the solution heat treatment in the age hardening process [9]. Moreover, other elements such as $\mathrm{Cr}$ can refine the eutectic silicon however the sludge phase can easily form with high $\mathrm{Cr}$ content and slow cooling rate [10]. Upon addition with Al-Sr alloy, it was dissolve into the melt and form the $\mathrm{SrAl}_{2} \mathrm{Si}_{2}$ compound [11] which increases the impurity twining for changed eutectic $\mathrm{Si}$ from acicular into a fibrous morphology.

The combination between the grain refiner and modifier of master alloys can enhance quality and mechanical properties of casting part [12]. Recently, there are many grain refiner and modifier were developed such Al-Ti-B-Sr and Al-B-Sr master alloys by producing various types of particles such as $\mathrm{TiB}_{2}, \mathrm{TiAl}_{3}$, $\mathrm{AlB}_{2}$ and $\mathrm{SrB}_{6}$ as the heterogeneous nucleation site and modification in the melt treatment process, simultaneously. The $\mathrm{Al}_{4} \mathrm{Sr}$ particle is found in the $\mathrm{Al}-\mathrm{Sr}$ or Al-B-Sr master alloys was dissolved when it was added into the melt during casting [13]. Then, Sr will affect to the eutectic reaction temperature (ERT) and modify microstructure of eutectic phase will be obtained [14].

Form many research papers, the size and morphology of various phases in the master alloy production depend on the melting temperature, cooling rate, chemical compositions and casting method. Ding reported that the blocky $\mathrm{TiAl}_{3}$ phase was fully refined grain size compared to combined the needle-like $\mathrm{TiAl}_{3}$ phase [15]. Liao reported that the size and morphology of $\mathrm{Al}_{4} \mathrm{Sr}$ phase from different processes affects to the modification efficiency [13]. Wang found that the morphologies of $\mathrm{TiAl}_{3}, \mathrm{TiB}_{2}, \mathrm{AlB}_{2}$ and $\mathrm{AlB}_{12}$ phases form different synthesis temperature of the Al-3\%Ti$3 \% \mathrm{~B}$ master alloy were effect to reduce the $\alpha$-Al phase in $\mathrm{Al}-\mathrm{Si}$ alloys [16]. Cui, reported $\mathrm{SrB}_{6}$ phase of Al-3B$5 \mathrm{Sr}$ master alloy can refine the $\alpha-\mathrm{Al}$ of A356 alloy but have not investigated the size and morphology on grain refinement and eutectic modification efficiencies [17].

This paper studied the effect of cooling rates on size and morphology of $\mathrm{AlB}_{2}$ and $\mathrm{SrB}_{6}$ particles in production of $\mathrm{Al}-3 \% \mathrm{~B}-3 \% \mathrm{Sr}$ master alloy. The comparison of grain refinement and eutectic modification efficiency in cast A356 alloy were discussed.

\section{Experimental procedures}

In order to develop and produce the $\mathrm{Al}-3 \% \mathrm{~B}-3 \% \mathrm{Sr}$ master alloy, the Al-6\%B alloy was melted by using a low frequency induction furnace at $900^{\circ} \mathrm{C}$. Then, the

\footnotetext{
* Corresponding author: weh@kmutnb.ac.th
} 
melt was added of the Al-10\% Sr master alloy and held for $30 \mathrm{~min}$. After that the melt was poured into a molds. There were two different cooling rates of casting for 0.2 and $10^{\circ} \mathrm{C} / \mathrm{s}$, respectively. The difference wall thickness of the molds between a stainless-steel cup and cylinder steel molds were used to control the cooling rate. The solidification curve of casting was detected by chromelalumel thermocouple with $0.5^{\circ} \mathrm{C} / \mathrm{s}$ in a stainless-steel cup by using the thermal analysis technique. The specimens were polished and etched by the Keller's reagent. The microstructure was analyzed by optical microscope. The grain refiner and modifier phase were identified by the scanning electron microscopy with energy dispersive spectroscopy (SEM-EDS) technique. The phase fraction of each phase was analyzed by the image analyzer as shown in table 1.

Table 1. Cooling and phase fraction of master alloys

\begin{tabular}{|c|c|c|c|c|}
\hline \multirow{2}{*}{ Master alloys } & \multirow{2}{*}{ Cooling rate } & \multicolumn{3}{|c|}{ Phase fraction (\%) } \\
\cline { 3 - 5 } & $\mathrm{AlB}_{2}$ & $\mathrm{SrB}_{6}$ & $\mathrm{Al}_{4} \mathrm{Sr}$ \\
\hline $\begin{array}{c}\mathrm{Al}-3 \% \mathrm{~B}-3 \% \mathrm{Sr} \\
\text { (M1 alloy) }\end{array}$ & $\begin{array}{c}0.2^{\circ} \mathrm{C} / \mathrm{s} \\
\text { (Slow cooling) }\end{array}$ & 0.34 & 3.88 & 0.38 \\
\hline $\begin{array}{c}\mathrm{Al}-3 \% \mathrm{~B}-3 \% \mathrm{Sr} \\
\text { (M2 alloy) }\end{array}$ & $\begin{array}{c}10^{\circ} \mathrm{C} / \mathrm{s} \\
\text { (Rapid cooling) }\end{array}$ & 0.32 & 3.43 & 0.27 \\
\hline
\end{tabular}

In the grain refinement and eutectic silicon modification efficiency tests, the $\mathrm{Al}-7 \% \mathrm{Si}-0.3 \% \mathrm{Mg}$ alloy was melted at $900^{\circ} \mathrm{C}$ by using the low frequency induction furnace. The Al-3\%B-3\% Sr master alloy was added into the melt with $4 \mathrm{wt} . \%$ and holding for $10-120$ min. The covering flux was used to prevent the hydrogen gas diffuse into the melt during casting. The Ar gas was used to remove hydrogen gas and various inclusions with flow rate $10 \mathrm{~L} / \mathrm{min}$. The melt was poured at $720^{\circ} \mathrm{C}$ into a stainless-steel cup with control cooling rate for $0.2^{\circ} \mathrm{C} / \mathrm{s}$. The specimen preparations of macrostructure and microstructure were grinded, polished and etched by the Keller's and Tucker's reagents, respectively. The grain size was measured by the linear intercept method according to ASTM E112.

\section{Result and discussion}

\subsection{Microstructure of Al-3\%B-3\%Sr master alloy}

Microstructures of $\mathrm{Al}-3 \% \mathrm{~B}-3 \% \mathrm{Sr}$ master alloy with resulted from different cooling rates of the production were shown in Fig.1 and Fig.2.

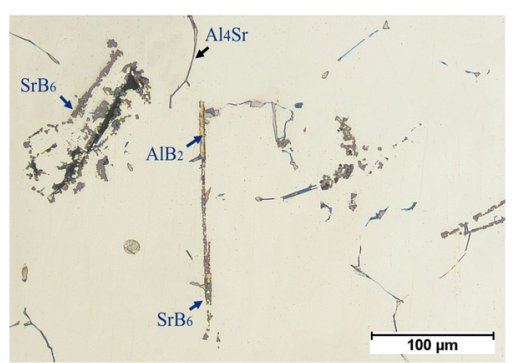

Fig. 1. Microstructure of $\mathrm{Al}-3 \% \mathrm{~B}-3 \% \mathrm{Sr}$ master alloy with cooling rate of $0.2^{\circ} \mathrm{C} / \mathrm{s}$
Each phase in the microstructures were identified by the SEM-EDS in order to clarify the composition. The microstructure of the M1 alloy (Slow cooling) consisted of solidified phase of $\mathrm{AlB}_{2}, \mathrm{SrB}_{6}$ and $\mathrm{Al}_{4} \mathrm{Sr}$ in the matrix of $\alpha-\mathrm{Al}$ as shown in Fig. 1 It can be seen that the $\mathrm{SrB}_{6}$ (gray-black) was blocky morphology. The $\mathrm{AlB}_{2}$ was surrounded by the $\mathrm{SrB}_{6}$ particle while $\mathrm{Al}_{4} \mathrm{Sr}$ was the plate-like morphology.

Microstructure of the M2 alloy (Rapid cooling) consisted of the smaller particles of $\mathrm{AlB}_{2}$, blocky $\mathrm{SrB}_{6}$ and $\mathrm{Al}_{4} \mathrm{Sr}$. It can be seen that the $\mathrm{SrB}_{6}$ was found in cluster, while $\mathrm{AlB}_{2}$ was uniform distribution as shown in Fig. 2. From phase fraction analyzed as shown in Table.1, it was found that the M1 alloy have higher amount of phase fraction than the M2 alloy.

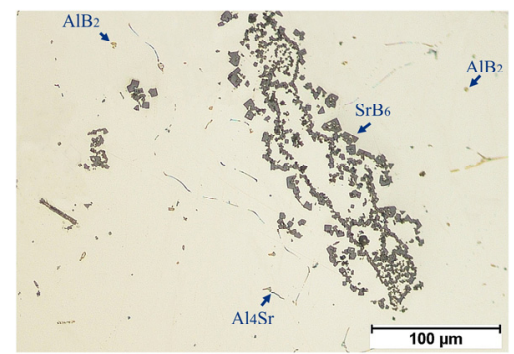

Fig. 2. Microstructure of $\mathrm{Al}-3 \% \mathrm{~B}-3 \% \mathrm{Sr}$ master alloy with cooling rate of $10^{\circ} \mathrm{C} / \mathrm{s}$.

\subsection{Microstructure of un-modified A356 alloy}

Fig. 3 (a-b) show the macrostructure and microstructure of un-modified A356 alloy which consisted of coarse grain size (Fig.3 (a)) and acicular eutectic Si (Fig.3(b)).
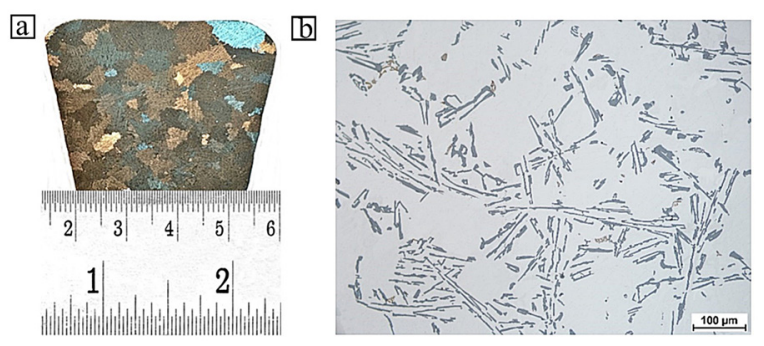

Fig. 3. Showed (a) macrostructure (b) microstructure of unmodified A356 alloy.

\subsection{Solidification and microstructure of modified A356 with M1 alloy}

Fig. 4 shows comparison of cooling curves of modified A356 by addition of M1 alloy with various holding times. The solidification behavior as observed from cooling curve, it was found smaller peaks of undercooling of $\alpha-\mathrm{Al}$ in comparison to cooling curve of un-modified $\mathrm{A} 356$. This is because $\mathrm{AlB}_{2}$ and $\mathrm{SrB}_{6}$ particles in master alloy act as the heterogeneous nucleation site. When comparison effect of holding time in furnace, it found that holding time in a range of 10$60 \mathrm{~min}$ specimens have smaller grain size compared to 120min specimen as shown in Fig.5.

The eutectic reaction temperature (ERT) of unmodified $\mathrm{A} 356$ is $578^{\circ} \mathrm{C}$ after cooling time in the mold 
for 110s. When addition of M1 alloy after holding in furnace for $10-30 \mathrm{~min}$, it was found that the ERT occurred at lower temperature of $572^{\circ} \mathrm{C}$ and increase cooling time to longer for $140 \mathrm{~s}$ and $153 \mathrm{~s}$, respectively. When holding in furnace for prolong time for $120 \mathrm{~min}$, the ERT occurred at $576^{\circ} \mathrm{C}$ with cooling time for $120 \mathrm{~s}$.

These solidification behaviors can be explained by the $\mathrm{Sr}$ in master alloy affect to ETR and solidification time as shown Fig. 6.

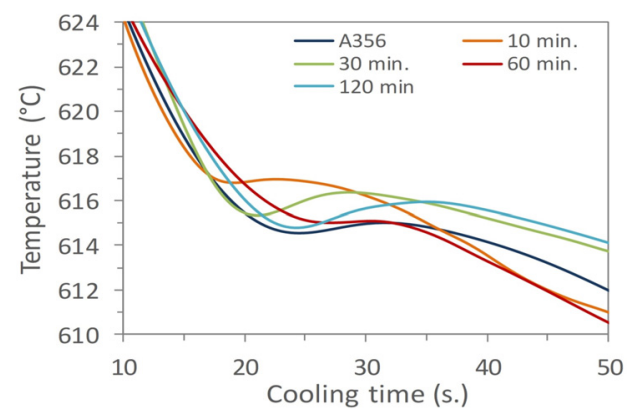

Fig. 4. Comparison of cooling curves at $\alpha-\mathrm{Al}$ formation with various holding time for 10 to $120 \mathrm{~min}$.

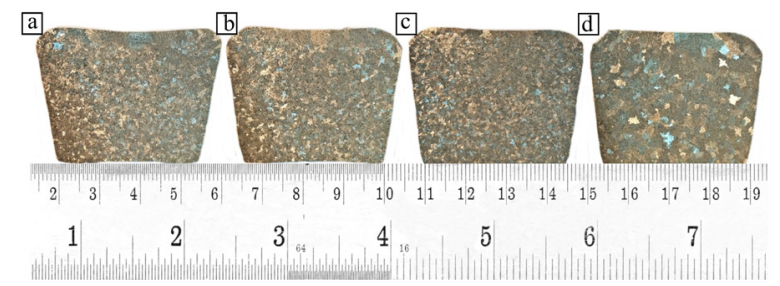

Fig. 5. Macrostructures of modified A356 by added M1 alloy (a) 10 (b) 30 (c) 60 (d) 120 min, respectively.

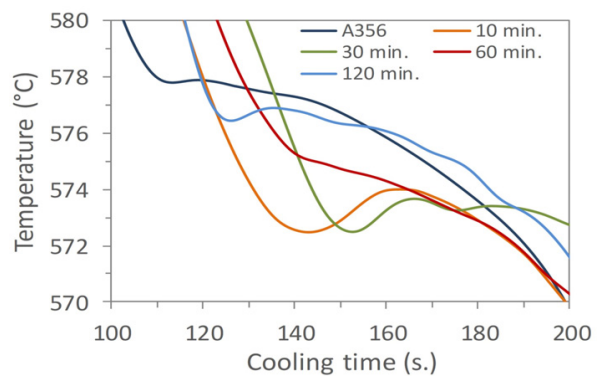

Fig. 6. Comparison of cooling curves at ERT with various holding time for 10-120 min.

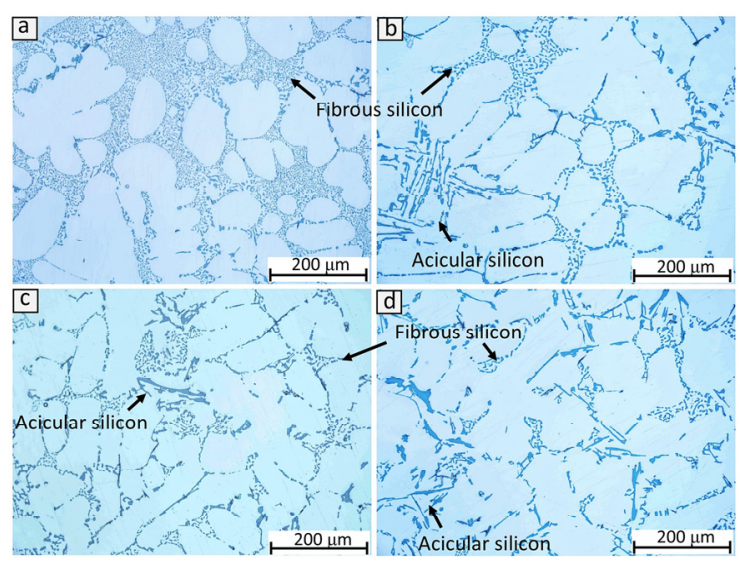

Fig. 7. Microstructure of modified A356 by addition of M1 alloy (a) 10 (b) 30 (c) 60 (d) 120 min, respectively.
Fig. 7 (a-d) show microstructure of various holding times. It is clearly seen that the $10 \mathrm{~min}$ specimen (Fig. 7 (a)) has finer fibrous $\mathrm{Si}$ compared to other specimens (Fig 7 (b-e)). Thus, when prolong holding time the modification efficiency was reduced.

\subsection{Solidification and microstructure of modified A356 with M2 alloy}

Fig. 8 shows comparison of cooling curves of modified A356 by added M2 alloy with various holding times. The solidification behavior, it was found smaller peaks of undercooling when the melt was added M2 alloy compared to un-modified A356. When comparison effect of holding time, it was found that holding time in a range $10-30 \mathrm{~min}$ specimens have smaller grain size compared to $60-120 \mathrm{~min}$ specimen as shown in Fig. 9.

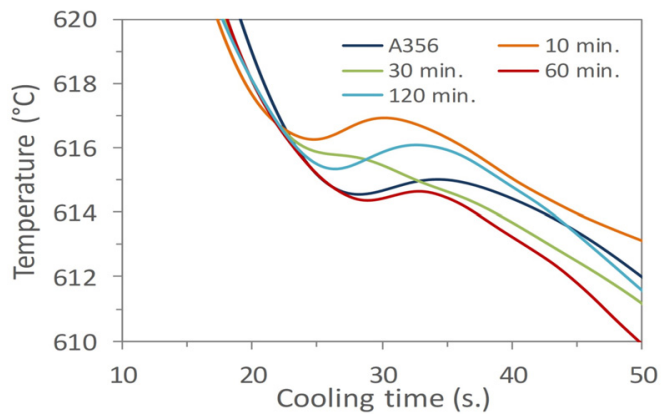

Fig. 8. Comparison of cooling curve at $\alpha$-Al formation with various holding time for 10 to $120 \mathrm{~min}$.

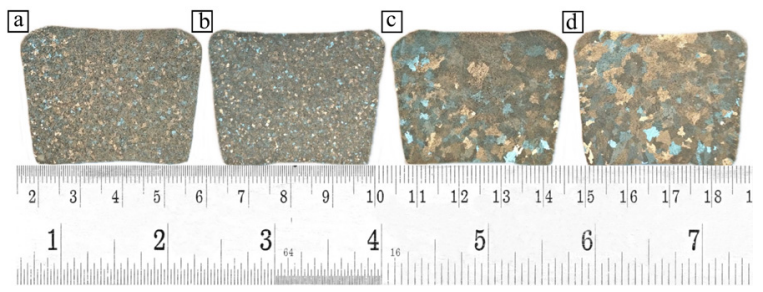

Fig. 9. Macrostructures of modified A356 by added M2 alloy (a) 10, (b) 30, (c) 60, (d) $120 \mathrm{~min}$, respectively.

When addition of M2 alloy after holding in furnace for $10-30 \mathrm{~min}$, it was found that the ERT occurred at lower temperature of $573^{\circ} \mathrm{C}$ and longer cooling time for $140 \mathrm{~s}$ and $145 \mathrm{~s}$, respectively. When holding in furnace for prolong time for $120 \mathrm{~min}$, the ERT occurred at $575.8^{\circ} \mathrm{C}$ and cooling time for 130s as shown Fig. 10.

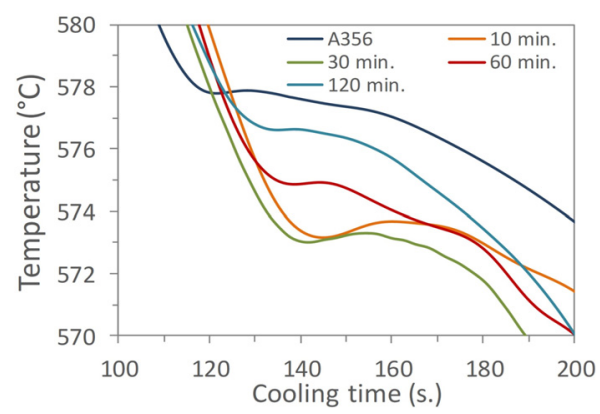

Fig. 10. Comparison of cooling curves at ERT with various holding time for 10-120 min. 
Fig. 11 (a-d) show microstructures of various holding times. It is clearly seen that the $60 \mathrm{~min}$ specimen has finer fibrous Si compared to 10-30min specimens (Fig. 11 (a-b)). When holding for prolong time the modification efficiency was reduced (Fig. 11 (d)).

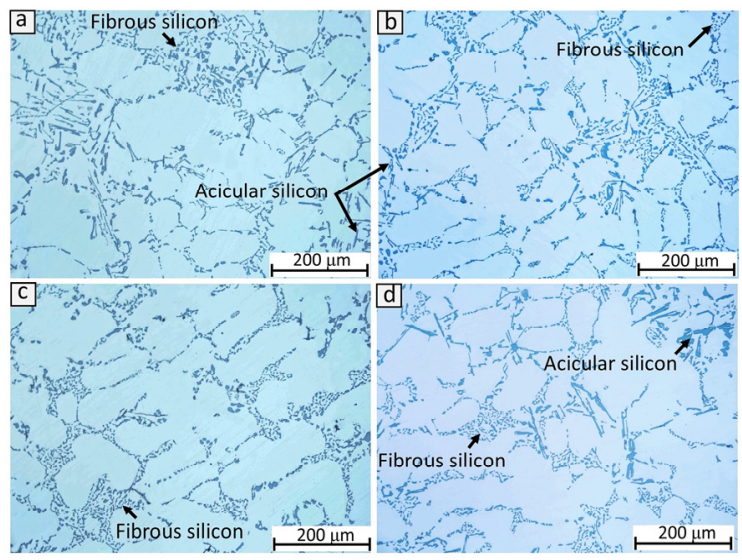

Fig. 11. Microstructure of alloy with M1 alloy (a) 10 (b) 30 (c) 60 (d) $120 \mathrm{~min}$, respectively.

\subsection{Effect of size and morphology of $\mathrm{AlB}_{2}$ and $\mathrm{SrB}_{6}$}

Form these experimental results, it can be discussed that addition of the M1 alloy with higher amount of $\mathrm{AlB}_{2}$ and $\mathrm{SrB}_{6}$ particles has higher grain refining efficiency than the M2 alloy as shown in Fig. 12. The M2 alloy has shorter efficiency time with in $30 \mathrm{~min}$ because a fine particles is easy dissolved into the melt when prolong holding time.

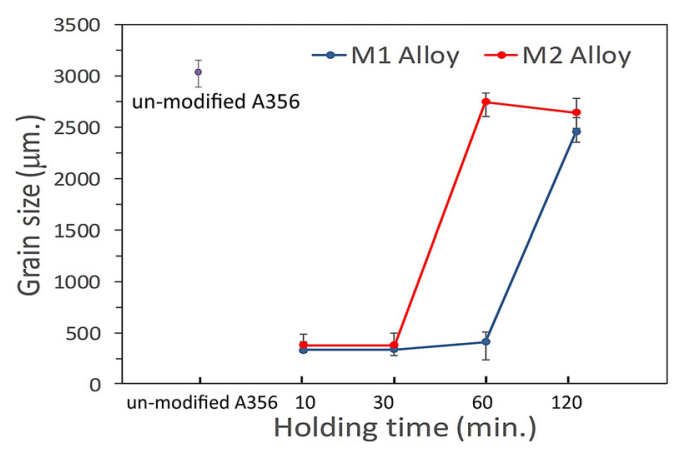

Fig. 12. Comparison of grain size with various holding time.

Moreover, the M1 alloy has higher modification efficiency than the M2 alloy in all period holding times, especially for $10 \mathrm{~min}$ specimen (Fig. 7 (a-b)). This is because the ERT of the modified A356 is become lower $5-6^{\circ} \mathrm{C}$ compared to the un-modified A356. It also found that the solidification time (ST) of the modified A356 was expended to $110 \mathrm{~s}$ to $140 \mathrm{~s}$, simultaneously. Thus, when the ERT reduced and ST shifted to longer (shift to right of Al-Si phase diagram) it should be achieved fine microstructure. Therefore, from these experimental results, the cooling rate of production of $\mathrm{Al}-3 \% \mathrm{~B}-3 \% \mathrm{Sr}$ master alloys is very important parameter in order to achieve high efficiency of grain refinement and modification.

\section{Conclusions}

1. The cooling rate of master alloy production affected to the size and morphology. The slow cooling have larger particle than rapid cooling.

2. The larger particle of $\mathrm{AlB}_{2}$ and $\mathrm{SrB}_{6}$ was higher efficiency than smaller particles.

3. The plate-like $\mathrm{Al}_{4} \mathrm{Sr}$ particle was better modifying the eutectic silicon compared to smaller particle.

4. The addition of M1 and M2 alloys were reduced of ERT and shifted ST to longer.

\section{References}

1. R. Lumley, Fundamentals of Aluminium Metallurgy, Production, Processing and Applications (Woodhead Publishing Limited, Great Abington, 2011)

2. P. Li, E.G. Kandalova, V.I. Nikitin, Materials Letters 59, 723 (2005)

3. Z. Chen, T. Wang, L. Gao, H. Fu, T. Li, Materials Science and Engineering A 553, 32 (2012)

4. C. Limmaneevichitr, W. Eidhed, Materials Science and Engineering A 355, 174 (2003)

5. P. S. Mohanty, J. E. Gruzleski, Acta mater 44, 3749 (1996)

6. V.P. Patel, H.R. Prajapati, International Journal of Engineering Research and Applications (IJERA) 2, 147 (2012)

7. J. Gilbert Kaufman, Elwin L. Rooy, Aluminum Alloy Castings: Properties, Processes, and Applications, (ASM International, OH, 2004)

8. S. Hegde, K. Narayan Prabhu, J Mater Sci 43, 3009 (2008)

9. Eidhed, W, Journal of Materials Science \& Technology 24, 29 (2008)

10. Eidhed, W, Journal of Materials Science \& Technology, 24, 45 (2008)

11. J. Barrirero, J. Li, M. Engstler, N. Ghafoor, P. Schumacher, M. Odén , F. Mücklich, Scripta Materialia 117, 16 (2016)

12. G. L. Liu, N. C. Si, Applied Mechanics and Materials 312, 396 (2013)

13. C. Liao, J. Chen, Y. Li, H. Chen, C. Pan, Progress in Natural Science: Materials International 24, 87 (2014)

14. G. Eisaabadi B., M. NouriR Beygi, M. Zarezadeh Mehrizi, A. Nouri, M. Ebrahimi, Shape Casting: 6th International Symposium (to be published)

15. W. Ding, T. Xia, W. Zhao, Materials 7, 3663 (2014)

16. T. Wang, H. Fu, Z. Chen, J. Xu, J. Zhu, F. Cao, T. Li, Journal of Alloys and Compounds 511, 45 (2012)

17. X.L. Cui, Y.Y. Wu, T Gao, X.F. Liu, Journal of Alloys and Compounds 615, 906 (2014) 